\title{
Patterns of acid reflux in complicated oesophagitis
}

\author{
D ROBERTSON, M ALDERSLEY, H SHEPHERD, AND C L SMITH
}

From the Professorial Medical Unit, Southampton General Hospital, Southampton

SUMMARY Oesophageal manometry and 24 hour ambulatory pH recordings from the distal oesophagus were carried out in 25 patients with complications of oesophagitis (stricture, Barrett's oesophagus or oesophageal ulcer) and compared with 25 patients with uncomplicated oesophagitis. Acid reflux was more severe in the complicated group with $26 \cdot 2 \%$ of time below $\mathrm{pH} 4$ compared with $11.3 \%$ in uncomplicated patients $(\mathrm{p}<0.01)$. This difference was most marked at night, when complicated patients had long periods of acio reflux with $35 \cdot 6 \%$ time less than $\mathrm{pH} 4$ compared with $5 \cdot 2 \%$ uncomplicated $(\mathrm{p}<0 \cdot()() 1)$. The mean duration of nocturnal acid reflux was $15 \cdot 4$ minutes $(2 \cdot 1$ minutes uncomplicated, $\mathrm{p}<() \cdot()() 1)$. Oesophageal motility was markedly abnormal in all groups, but with no demonstrable differences in lower oesophageal sphincter pressure or peristalsis between the groups. Patients with complications of oesophagitis have different patterns of acid reflux from uncomplicated patients, with prolonged nocturnal bathing of the oesophageal mucosa, which may be the cause of stricture formation, metaplasia, or ulceration.

Oesophagitis is thought to be the result of abnormal gastro-oesophageal acid reflux in most patients. A few short lived acid reflux episodes occur in most normal individuals each day, but patients with oesophagitis may have more frequent, prolonged reflux, poor clearance of refluxed material, more potent reflux material, or diminished mucosal resistance.' Abnormal oesophageal motility may explain some of these abnormalities: there is abnormal peristalsis in the body of the oesophagus ${ }^{2}$ and impaired tone and coordination in the lower oesophageal sphincter. ${ }^{3}$ These abnormalities of motility may be secondary to acid reflux, because they improve after an effective antireflux manoeuvre, ${ }^{+}$and get worse with more severe oesophagitis.' Recent studies using ambulatory $\mathrm{pH}$ recordings in the distal oesophagus have confirmed the association of oesophagitis with excessive reflux of gastric acid" and documented the response to treatment. 'Most patients with peptic oesophagitis respond to medical measures such as $\mathrm{H}_{2}$ antagonists, but there is a strong tendency for symp-

\footnotetext{
Address for correspondence: Dr D) Robertson, Professorial Medical Unit. Room I.I)6. Level D). South L aboratory and Pathology Block, Southampton General Hospital. Tremona Road. Southampton S(O) 4XY.

Received for publication 9 April 1987.
}

toms to recur after cessation of treatment. ${ }^{*}$ Some patients, however, will develop complications of oesophagitis such as stricture formation, Barrett's oesophagus or oesophageal ulceration, all of which are thought to be caused by excessive exposure of the oesophageal mucosa to acid, although not all patients presenting with these complications have a previous history of oesophagitis.

We have compared the pattern and severity of gastro-oesophageal reflux and oesophageal motility in patients presenting with these complications of oesophagitis with uncomplicated patients.

\section{Methods}

\section{PATIENTS}

Twenty five patients with uncomplicated oesophagitis were studied, graded as follows:" (grade 1, 7; grade 2,11 ; grade 3,7 ; mean age 43 years - range $18-76 ; 11$ men, 14 women) and 25 patients with complications (Grade 4 oesophagitis - strictures 12, seven of whom were studied before and after dilatation, oesophageal ulcers six, Barrett's oesophagus seven; mean age 47 years, range $30-83 ; 12$ men, 13 women).

All patients were gastroscoped the day before this 
study. All drugs were stopped four days before investigation. A stricture was defined as a narrowing of the oesophageal lumen, causing dysphagia and requiring dilatation. Malignancy was excluded by biopsy and repeat gastroscopy. An oesophageal ulcer was defined as a deep ulcer occurring in squamous epithelium which was benign on biopsy and repeat gastroscopy. Barrett's oesophagus was defined as an oesophagus with a columnar epithelium with the appropriate manometric characteristics.

Manometry was performed using a Hewlett Packard physiological recording system with an Arndorfer capillary perfusion system attached to a $125 \mathrm{~cm}$ triple lumen catheter with the perfusion ports $5 \mathrm{~cm}$ apart. Lower oesophageal sphincter pressure was measured using the station pullthrough technique. Oesophageal peristalsis was assessed with $10 \times 3 \mathrm{ml}$ swallows with the lower opening of the triple lumen tube just above the lower oesophageal sphincter, and then with the highest opening just below cricopharyngeus. The number of abnormal waves (simultaneous, repetitive, variable amplitude, incompletely propagated or spontaneous waves) was recorded. Twenty four hour ambulatory $\mathrm{pH}$ record- ings were carried out with the antimony $\mathrm{pH}$ probe positioned $5 \mathrm{~cm}$ above the manometrically defined lower oesophageal sphincter and connected to a portable digital recorder (Synectics Digitrapper Mark II 6100). There were no dietary restrictions and all studies were done on ambulatory outpatients. Data were recorded and analysed on an IBM PC and statistical analysis undertaken using the Wilcoxson's rank-sum test for paired or unpaired data.

\section{Results}

Acid reflux was more severe in complicated patients. Two typical tracings of the $\mathrm{pH}$ record obtained from the lower oesophagus are shown in Figure 1; (1) a recording from a patient with uncomplicated oesophagitis (upper recording) and (2) a recording from a patient with Barrett's oesophagus (lower recording). The mean percentage time below $\mathrm{pH} 4$ ( 24 hours) was $26.2 \%$ for those with complications, compared with $11 \cdot 3 \%$ in uncomplicated patients $(\mathrm{p}<0 \cdot 01)$ (Fig. 2$)$. This difference was attributable to increased acid reflux in the nocturnal period (midnight to $8 \mathrm{am}$ ) with a mean $\mathrm{pH}<4,35 \cdot 6 \%$ in complications, compared
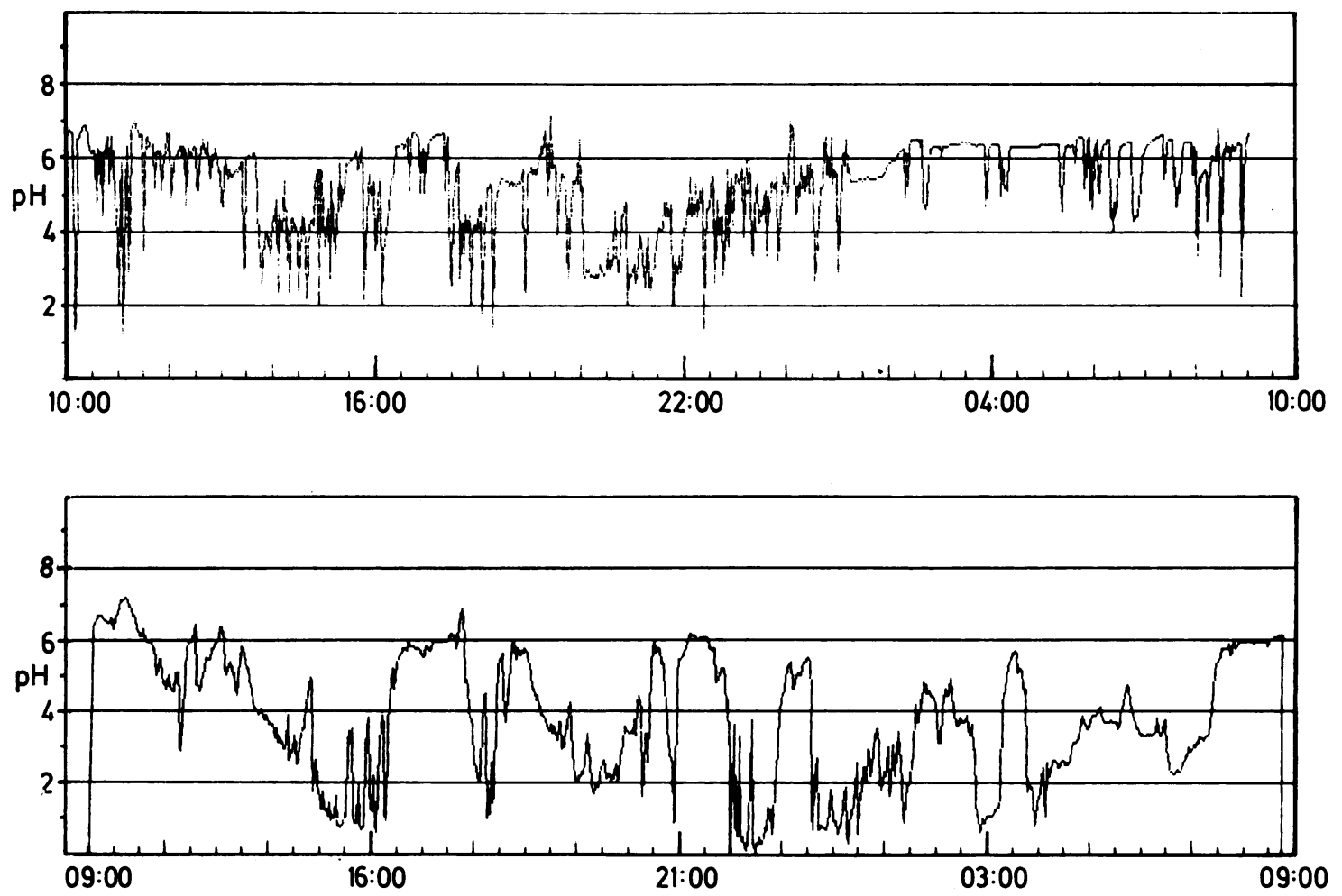

Fig. 1 Ambulatory $\mathrm{pH}$ recording from a patient with uncomplicated oesophagitis (upper recording) showing short lived postprandial acid reflux with minimal nocturnal reflux. Lower recording is from a patient with Barrett's oesophagus, and shows prolonged episodes of daytime and nocturnal acid reflux. 


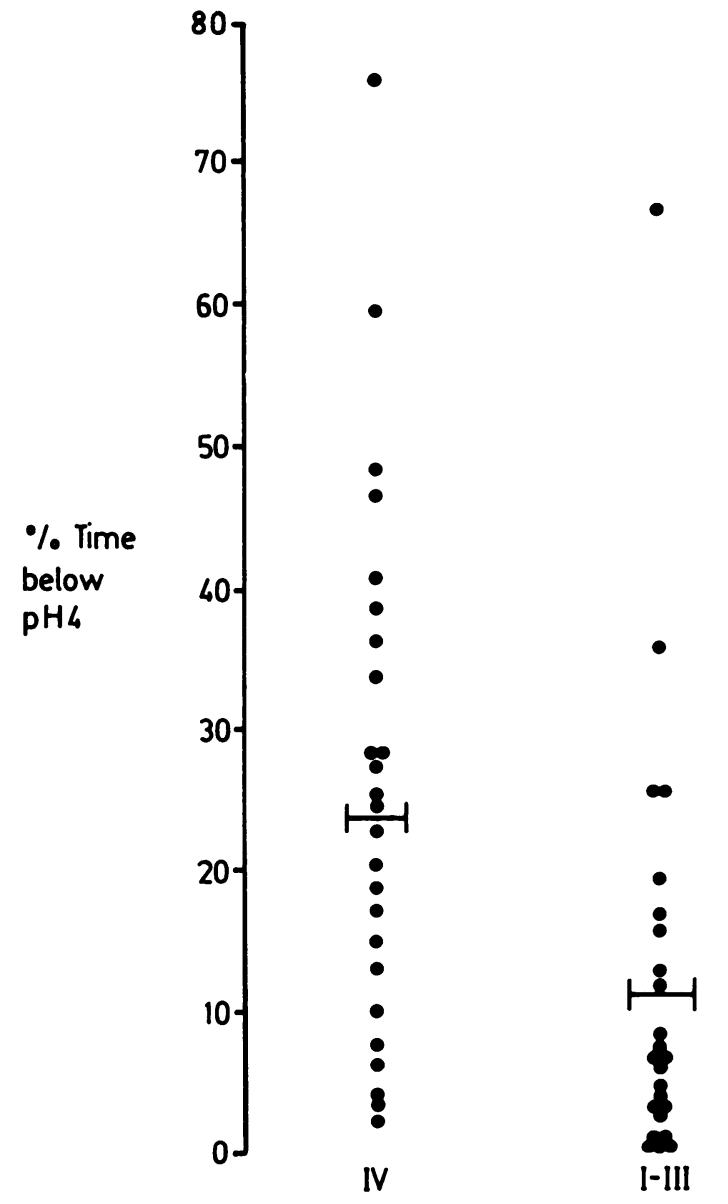

Fig. 2 Twenty four hour ambulatory pH data showing $\%$ time below pH 4 from 25 patients with complications of oesophagitis (IV) which is significantly greater than in uncomplicated oesophagitis $(I-I I I),(p<0 \cdot 01)$.

with $5 \cdot 2 \%$ in oesophagitis alone $(\mathrm{p}<0 \cdot 001)$ (Fig. 3$)$. During the daytime period ( 8 am to midnight), the results were similar - $17 \%$ complications $v 13 \%$ oesophagitis.

The frequency of reflux below $\mathrm{pH} 4$ in the 24 hour period was similar in both groups $(0-80$ reflux episodes, mean 29 in oesophagitis, seven to 79 reflux episodes, mean 36 in complications), but the duration was significantly greater overall (mean 10.1 minutes) in those with complications, compared with 4.3 minutes in oesophagitis, $p<0 \cdot 01$ ). This difference was most marked in the nocturnal period, where the mean duration of acid reflux was 15.4 minutes with complications, compared with $2 \cdot 1$ minutes in oesophagitis alone $(\mathrm{p}<0 \cdot 001)$.

There were no significant differences in acid reflux between different degrees of oesophagitis or between the different complications of oesophagitis (Table 1).

Patients with strictures measured before and 24 hours after dilatation showed a mean increase in acid reflux from $20 \cdot 3 \%$ to $31.4 \%$ (NS) as a result of the dilatation procedure (Fig. 4).

Abnormalities of oesophageal motility were very common in both groups: there were abnormal peristaltic waves in 6.9 of 20 swallows in oesophagitis, and $7 \cdot 4$ of 20 swallows in complications (NS). The lower oesophageal sphincter was identified in 47

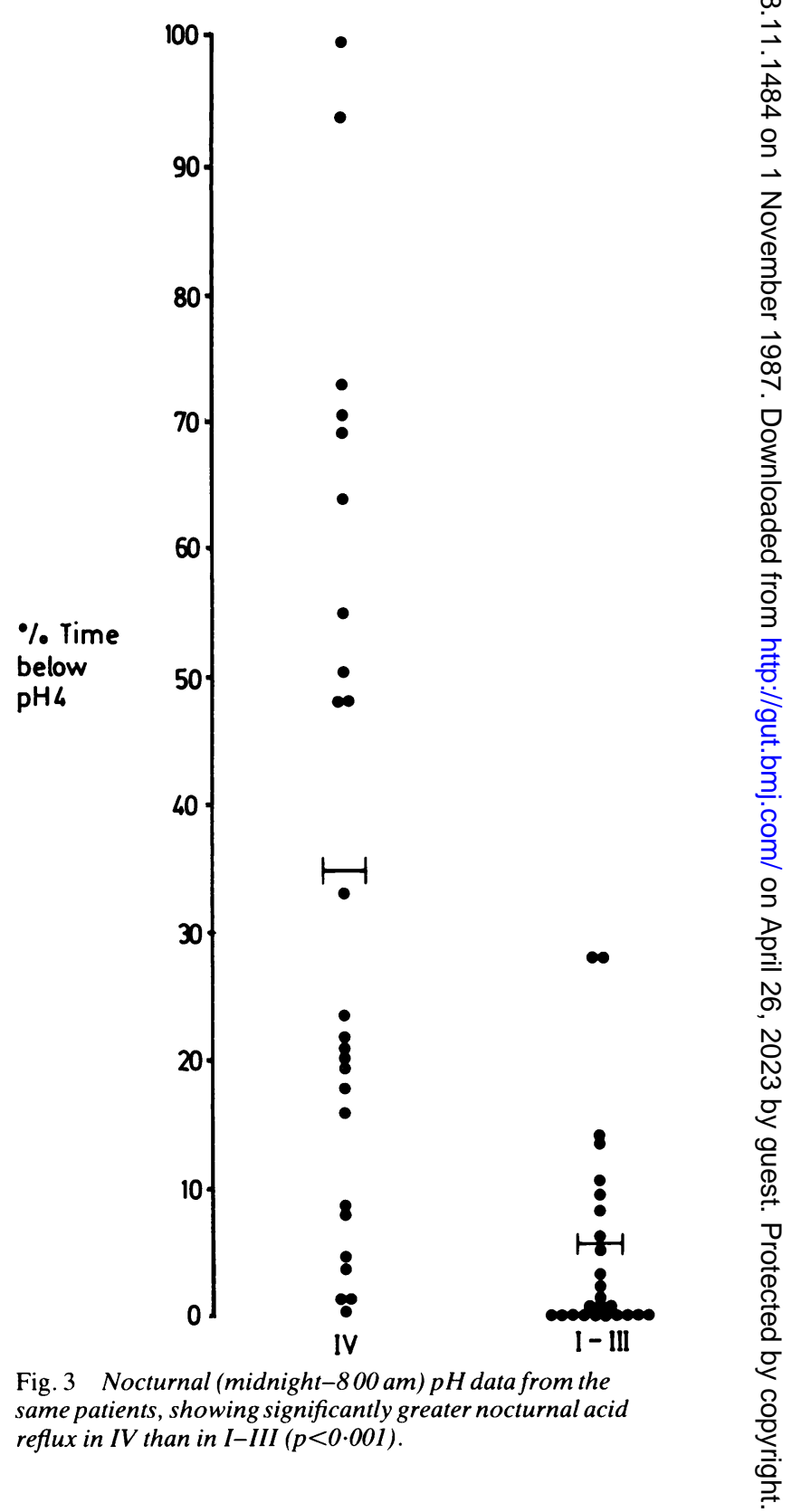


Table 1 Twenty four hour ambulatory $\mathrm{pH}$ values graded by severity of oesophagitis and the nature of complications. There is a trend to increasing severity of acid reflux in more severe grades of oesophagitis which does not reach statistical significance. There are no significant differences in pattern or severity of acid reflux in the various complications of oesophagitis

\begin{tabular}{lcc}
\hline Grade of oesophagitis & Number & $\begin{array}{l}\text { \% time below pH4 } \\
\text { (mean and range) }\end{array}$ \\
\hline 1 & 7 & $8 \cdot 8(2 \cdot 0-19 \cdot 4)$ \\
2 & 11 & $10 \cdot 2(0-25 \cdot 3)$ \\
3 & 7 & $15 \cdot 7(2 \cdot 8-67 \cdot 0)$ \\
Complication & & \\
Stricture (after dilatation) & 12 & $30 \cdot 5(2 \cdot 3-75 \cdot 7)$ \\
Ulcer & 6 & $22 \cdot 6(7 \cdot 7-48 \cdot 1)$ \\
Barrett's & 7 & $22 \cdot 0(6 \cdot 3-41 \cdot 0)$ \\
\hline
\end{tabular}

patients but could not be identified in three patients with strictures. The mean resting pressure was 31 $\mathrm{mm} \mathrm{Hg} \mathrm{(6-62)} \mathrm{in} \mathrm{oesophagitis,} \mathrm{and} 24 \mathrm{~mm} \mathrm{Hg} \mathrm{(4-70)}$ in complications (NS).

\section{Discussion}

We have shown that patients with complications of oesophagitis have more severe acid reflux than those with simple uncomplicated disease. This is largely because of prolonged periods of acid reflux at night. Presumably, tissue damage leading to stricture formation, metaplasia or ulceration occurs during these long periods of 'acid bathing' of the oesophagus which are usually asymptomatic and which are rarely seen in uncomplicated patients. In contrast, patients with oesophagitis usually have postprandial reflux associated with chest pain or heartburn. It is not clear whether these differing patterns of reflux are a result of different abnormalities or occur as a result of the tissue disruption associated with the complications. It appears that it is the nocturnal reflux which is of primary importance in those with complications in view of the similarity of reflux patterns in these patients, despite the differing natures of their complications and the fact that complications do not cause demonstrable impairment of the lower oesophageal sphincter compared with those with uncomplicated oesophagitis. The abnormal activity in the body of the oesophagus was similar in both groups of patients, and recent evidence has shown that in oesophagitis this may be secondary to acid reflux rather than a primary phenomenon, as the abnormal motility usually improves after an effective antireflux manoeuvre. ${ }^{+}$

It has been suggested that three hour postprandial ambulatory $\mathrm{pH}$ studies will provide as much information as a full 24 hour study," but these observations suggest that, while similar results will be obtained in patients with oesophagitis, important abnormal nocturnal reflux patterns will be overlooked using the three hour study period in patients with complications. We do not know whether similar acid reflux patterns occur before the development of complications, but if so then identification of these patients at an earlier stage of severity of oesophagitis may prevent the development of complications.

The few patients with moderately severe nocturnal reflux in the oesophagitis group (Fig. 2) may be those destined to develop complications, but aggressive treatment may be able to prevent this. There was a marginal increase in acid reflux after dilatation of oesophageal strictures - attributable to the two patients with normal values before dilatation in whom marked acid reflux was shown after dilatation (Fig. 4) - in keeping with previous studies where dilatation of strictures did not worsen gastrooesophageal reflux."

The absence of significant nocturnal reflux in the majority of patients with oesophagitis suggests that

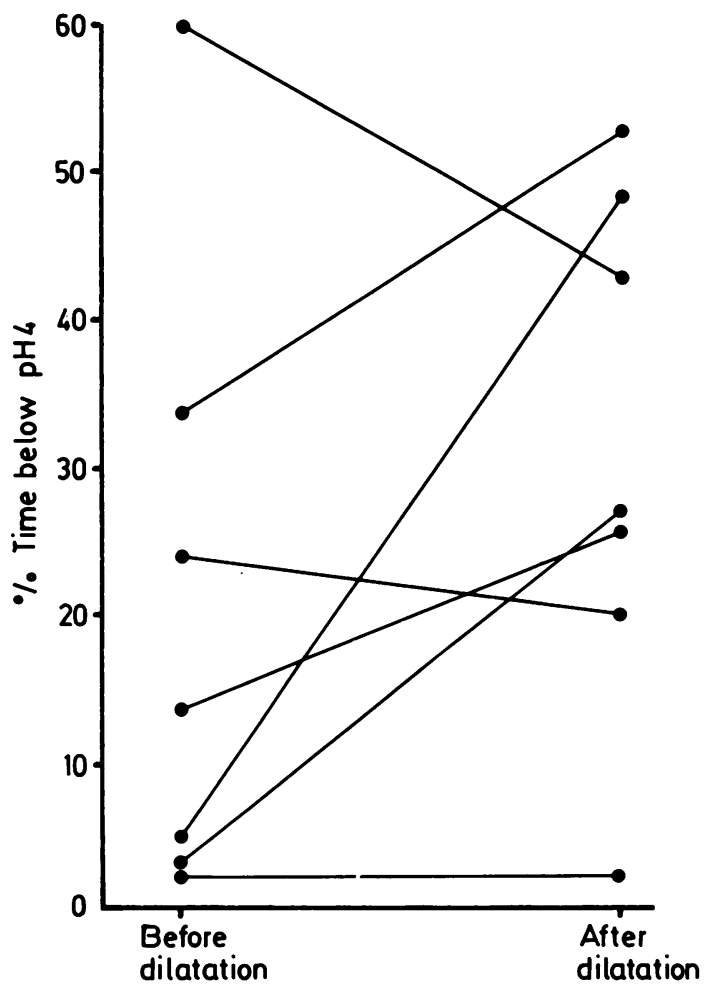

Fig. 4 Twenty four hour ambulatory $\mathrm{pH}$ data on seven patients measured before and four days after oesophageal dilatation. There is a non-significant increase in acid reflux $(20.3 \%$ to $31.4 \%)$, because of two patients with normal values before dilatation having marked acid reflux after dilatation. 
Table 2 Peristaltic abnormalities recorded during manometry (expressed as mean percentage of abnormal waves)

\begin{tabular}{lcc}
\hline & Oesophagitis & Complications \\
\hline Simultaneous & $4 \cdot 5$ & $9 \cdot 0$ \\
Repetitive & $11 \cdot 6$ & $5 \cdot 4$ \\
Variable amplitude & $3 \cdot 1$ & $7 \cdot 7$ \\
Incomplete propagation & $8 \cdot 7$ & $13 \cdot 5$ \\
Spontancous & $6 \cdot 6$ & $1 \cdot 4$ \\
Total abnormal waves & $34 \cdot 5$ & 37 \\
\hline
\end{tabular}

the competence of the lower oesophageal sphincter is maintained throughout the night, but that the patients with complications have intermittent relaxation of the sphincter, together with reduced clearing, allowing reflux of acid which is severe and prolonged. We were unable to identify a specific abnormality of oesophageal motility in these patients, however, and although there was a non-significant reduction in lower oesophageal sphincter pressure in the group with complications, this was attributable to the three patients in whom the lower oesophageal sphincter could not be identified, and was recorded as 0 . It may be that there is a specific abnormality of oesophageal motility detectable only at night, or that other factors such as delayed gastric emptying or excessive nocturnal gastric acid secretion are more important in this group.

The treatment of oesophagitis and its complications remains unsatisfactory, with persisting morbidity in many patients despite medical or surgical intervention. The demonstration of severe nocturnal reflux has important implications for treatment, and clearly nocturnal suppression of acid reflux is important. We have previously shown that reduction of acid reflux to normal values only occurs in about $50 \%$ of subjects with oesophagitis on high doses of $\mathrm{H}_{2}$ antagonists, ${ }^{7}$ and surgical prevention of acid reflux may be important in this group of patients with complications who fail to respond to medical measures. The present state of knowledge does not allow us to identify patients who require surgery on the basis of ambulatory $\mathrm{pH}$ studies.

\section{References}

1 Dodds WJ, Hogan WJ, Helm JF, Dent J. Pathogenesis of reflux oesophagitis. Gastroenterology 1981; 81: 376-9.

2 Booth DJ, Kemmerer WD, Skinner DB. Acid clearing from the distal oesophagus. Arch Surg 1968; 76: 732-4.

3 Corraziari E, Bontemp I, Anzini F, Torsoli A. Motility of the distal oesophagus and gastro-oesophageal reflux. Gut 1984; $25: 7-13$.

4 Gill RC, Bowes HL, Murphy PP, Kingma YJ. Esophageal motor abnormalities in gastroesophageal reflux and the effects of fundoplication. Gastroenterology 1986; 91: 364-9.

5 Kahrilas PJ, Dodds WJ, Hogan WJ, Kern M, Arndorfer RC, Reece A. Esophageal peristaltic dysfunction in peptic oesophagitis. Gastroenterology 1986; 91: 879-904.

6 Dodds WJ, Dent J, Hogan WJ. Mechanisms of gastroesophageal reflux in patients with reflux oesophagitis. N Engl J Med 1982; 307: 1547-52.

7 Robertson DAF, Aldersley M, Shepherd H, Lloyd R, Smith $\mathrm{CL}$. $\mathrm{H}_{2}$ antagonists in the treatment of reflux oesophagitis: can physiological studies predict the response? Gut 1987; 28: 946-9.

8 Koelz HR, Birchler R, Bretholz A, et al. Healing and relapse of reflux oesophagitis during treatment with ranitidine. Gastroenterology 1986; 91: 1198-205.

9 Savary M, Miller G. In: The esophagus. Switzerland: Gassmann, 1978.

10 Fink SM, McCallum RW. The role of prolonged esophageal $\mathrm{pH}$ monitoring in the diagnosis of gastroesophageal reflux. JAMA 1984; 252: 1160-4.

11 Penagini R, Evans PF, Trotman IF. Dilatation of peptic oesophageal strictures: is it really beneficial? Gastroenterology 1986; 90: 1582 . 